Health Informatics - An International Journal (HIIJ) Vol.7, No.1, February 2018

\title{
Design Of RLE Scorer Web Forms And Nursing Students Efficacy In Parenteral Drug Admin At Tobruk UNIVERSITY
}

\author{
James Neil B. Mendoza ${ }^{1}$, Dorothy G. Buhat-Mendoza ${ }^{2}$, Noraliza N. Ingua ${ }^{3}$ \\ ${ }^{1}$ Lecturer - Computer Subjects, College of Nursing, Tobruk University, Libya \\ ${ }^{2}$ Lecturer - Nursing Subjects, College of Nursing, Tobruk University, Libya \\ ${ }^{3}$ Lecturer - Nursing Subjects, College of Nursing, Tobruk University, Libya
}

\begin{abstract}
Related Learning Experience or RLE is acourse offered in Tobruk University College of Nursing for $1^{\text {st }}$ year and $2^{\text {nd }}$ year students to prepare them for actual scenario in the hospital by practising skills related to Nursing and Health care. Team teaching is used to perform this activity and evaluated by Return Demonstration in the laboratory class and once more in the Final Return Demonstration or final exam. Tabulating all procedures and steps is a tedious matter doing it manually. In this study the proponents designed an RLE Scorer web forms based on Google survey forms to collect students performance and to computer for their equivalent marks. The focus of the study is in RLE 3 or parenteral drug administration. The collected data was saved in the Google drive and downloaded later; the results were treated statistically to find the mean score in all 5 procedures of RLE 3, and to find the difference between male and female respondents and the difference of variance based on rating. It was shown that the students performed generally well reaching the passing mark. The male students fared better in all procedures compared to femalebut there was no significant difference established. The purpose of the study is to encourage technological adaptation in collecting performances of nursing students, promoting team teaching in training of nursing skills in RLE thus supporting quality nursing education and nursing informatics.
\end{abstract}

\section{KEYWORDS}

Nursing Informatics, Related Learning Experience, Parenteral Drug Administration, Computer

\section{INTRODUCTION}

Nursing students recognize the significance of team teaching, practical return demonstration, and hospitalexposure towards excellent clinical nursing practice [1]. Proper nursing care for patients needs intensive practice [2]. Appropriate management of medication is an essential aspect of nursing practice to avoid problems or complication with the patients [3, 4]. Continuous experiences of the student nurses' in a variety of practical learning strategies is an effective means of acquiring neededskills set to increasing knowledge, skills, attitude and values to become an excellent nurse practitioner [1]. In team teaching all assigned teachers actively share the instruction of content and skills to their students',they also accept equal responsibility for the education of all students and are dynamically involved throughout the class period [5]. For the improvement in their performance in the hospital students must be exposed to practical demonstration in the classroom laboratory [6]. Students would be able to apply things learned at school in real situation or hospital scenario and able to exercise the procedure they performed in the laboratory [7].The advantage of using team teaching strategy includes: having various teaching styles and activities presented to the learners, and having more time for one on one and small group instruction [8]. The strategies of team teaching are having a group of teachers who

DOI: $10.5121 /$ hiij.2018.7101 
work together in planning, conducting and evaluating the learning activities for the same group of learners or to put it simply a team work between two qualified instructors together making presentations to the class [1]. Teachers using the said approach should prepare and plan to stimulate student in learning experience [9]. In Tobruk University this is performed in RLE or Related Learning Experience, a course offered for $1^{\text {st }}$ and $2^{\text {nd }}$ year students for 4 semesters where they were trained before doing clinical practice in their higher year and hospital scenario. Ifthe Practical Return Demonstration demonstrated by the clinical instructor on the procedure in nursing laboratory is followed up with return demonstration of the nursing students, it would emphasize greater understanding to the purpose and responsibility of a nurse on why taking care of the patient is important [1].

RLE 3 is a course offered in the $1^{\text {st }}$ semester of $2^{\text {nd }}$ year class in College of Nursing, Tobruk University. The focus of this course is parenteral drug administration also known as injection using a needle and a syringe [2]. There are 5 main procedure the student must master to finish the course; withdrawing medication from a vial, withdrawing medication from ampule, intradermal injection, intramuscular injection and subcutaneous injection. Procedures followed in these skills were adapted from Delmar's [2]. An intradermal injection is a method used to administer medications just below the skin, given for slow absorption of potent medication due to the less richly supplied blood vessels of this layer [2]. Intramuscular injection is a method used to administer medications into the deep muscle tissue for the purpose of quick absorption due to the richly supplied blood vessels in the muscle [11, 12].A subcutaneous injection is a method used to administer medications into the loose connective tissuesjust below the dermis of the skin, given especially ifmedicationsdo not need to be absorbed as quickly as thosegiven intramuscularly dueto the less richly supplied blood vessels in the subcutaneoustissue [2]. Before injection wasto be administered to patients, the students or practitioners must withdraw medication from a vial or ampoules. Vials are often used to package multi-dose or single-doseparenteral medication; it is a small glass bottlewith a rubber seal at the top [2]. Ampoules (also spelled ampule) are containers thathold a single dose of medication;it wasmade of clear glass and have a distinctive shape witha constricted neck [2]. Currently to assess the students the clinical instructor uses a checklist of procedures, rating every step from 3 as highest score and 0 as the lowest. Then it was tallied to get a sum, divide it to the number of items to get performance grade for each skill.All 5 procedures will then be computed for its average, done manually by clinical instructors. A time consuming process considering the number of students to assess during return demonstration in the classroom and in their final return demonstration considered as their final exam.

The adoption of Electronic Health Records has increased in recent years so is technological advancement in any field. Discrete data elements are more widely available which can be leveraged for secondary use [13]. The term eHealth by definition is defined as "the cost- effective and secure use of information and communicationstechnologies in support of health and healthrelated fields, including healthcare services, health surveillance, health education, knowledge and research" [14]. The goal of eHealth is toimprove the cooperation and coordination of healthcare, in order to improve the quality of careand reduce the cost of care at the same time [15]. The definition and purpose of e-health can be adapted in the students' evaluation in RLE where performance can be encoded electronically. To make development easier, efficient and portable the use of Google Docs, Google Sheets, and Google Slides were being utilized by developers. These Google suits are a word processor, a spreadsheet and a presentation program respectively, all part of a free, web-based software office suite offered by Google within its Google Drive service. The three apps are available as web application, and as mobile apps for Android and iOS [16] were developers can take advantage of mobile-computing. To create the survey forms Google forms will be used by the researchers. Google forms is a tool that allows collecting information from users via a personalized survey or quiz,the information is then 
collected and automatically connected to a spreadsheet where it is populated with the survey and quiz responses [17]. Certainly, 'mobility' is a characteristic of a mobile computing environmentwhere the user is able to continue his/her work seamlessly wherever he/she is [18].

In this study the researchers designed a simple RLE scorer web forms with the ability to collect the data in the cloud to be used for computation of the students return demonstration evaluation. Since it is both a web and mobile app, the evaluators can use their smart phones and tablets for data recording online.The assigned tabulator will just export the data collected in a spreadsheet for easy computation. The recorded scores would then be treated statistically to find the average score, standard deviation and adjectival rating. To test the difference of the mean score between male and female students an independent t-test and p-value would be computed. To test the difference of variance between the students rating, ANOVA will be utilized. The main purpose of the application is to ease the recording and computation by doing it electronically thus encouraging technological adaptation. The objective in the collection of results is to present and analyse the actual performance of the students' in common parenteral drug preparation and administration. The app and data collection would be limited for RLE 3, $2^{\text {nd }}$ year students of College of Nursing in Tobruk University. The result of the study is also intended to promote Nursing Informatics.

\section{Materials AND Methods}

The research uses experimental design on the web app and a descriptive non-experimental design for analysis of respondent performance in RLE 3 procedure's drug administration. Population assessment respondents will be the $2^{\text {nd }}$ year students of Related Nursing Experience 3 of College of Nursing. The study used the return demonstration procedure used in their final practical exam. The study aims to find out the nursing student's performance on parenteral drug administration and employ the RLE 3 Scorer Web Formsas evaluation tool on classroom performance and exams atTobruk University.

\subsection{Study Population}

The respondents consisted of 55 nursing students who recently took RLE 3 course from $2^{\text {nd }}$ year. The whole $2^{\text {nd }}$ year classwho attended the classroom and laboratory activities including the final exam was utilized in the study.To determine their current efficacy the study will present their performance in the return demonstration exam.

\subsection{Research Tools/Instrument}

The researcher uses a clinical instructor made procedure currently used as a checklist/evaluation tool for RLE 3 class which focuses on parenteral drug administration. There are 5 procedure being used, withdrawing medication from a vial, and withdrawing medication from ampule, intradermal injection, intramuscular injection and subcutaneous injection.

\subsection{Data Measures}

To permit ease of analysis collected data were tallied and organized into tables. Frequency distribution is used to count the number of respondents on the equivalent rating. Measures of central tendency like weighted mean and standard deviation were used to look for variation in the relative contribution of individual data values to the mean. Independent t-test was used to compare the means of perception between male and female students. ANOVA was used to get the difference in the variance when grouped according to rating. 
The computed results are then analysed with the use of an interpretation with specific mean score ranges and a subsequent adjectival interpretation. Shown below is the interpretation used for study in terms of nursing student's efficacy in parenteral drug administration.

Table 1: Interpretation of student's efficacy in Parenteral Drug Administration

\begin{tabular}{|c|c|}
\hline Range & Adjectival Interpretation \\
\hline $90-100$ & Excellent \\
\hline $80-89$ & Very Good \\
\hline $70-79$ & Good \\
\hline $60-69$ & Passed \\
\hline $50-59$ & Needs Improvement \\
\hline Below 50 & Poor \\
\hline
\end{tabular}

\subsection{Development Technique}

The proponent utilized a cloud based development approach in the creation of the RLE Scorer Web Formsbased on NPL or Non- Procedural Language techniques. Google forms were used in the development of checklist/procedure for data collection. It is the vital tool which uses the nonprocedural language for report generation, database query, datamanipulation, user interface, codegeneration, spread sheet capabilities and more [19].

\subsection{Software Tools}

The researchers used RLE web Formsto collect the data, exporting the result as a CSV file then attaching it to a ready made tally sheet in spreadsheet format permitting the data to be computed using sum,average for mean score, stdev for standard deviation sample size. Tallied valuesundergone data analysis tool pack to get the difference of mean between the gender of students by computing for $\mathrm{t}$-test and $\mathrm{p}$ value.

\section{RLE SCORER WEB FORMS}

Student performance were recorded and extracted in RLE Scorer web forms, figures will be used to present the screen shot of the system during operation. Manual computation method will also be presented descriptively.

\subsection{Manual Computation}

Related Learning Experience is a course offered for Bachelor's of Science in Nursing at Tobruk University for $1^{\text {st }}$ year and $2^{\text {nd }}$ year. There are four RLE's, RLE 1 and RLE 2 for $1^{\text {st }}$ year, RLE 3 and RLE 4 for $2^{\text {nd }}$ year. The grading system composed of class attendance and quizzes for $20 \%$, laboratory return demonstration $40 \%$ and final return demonstration (final exam) at $40 \%$. Both return demonstration (laboratory and final exam) activity uses the same set of checklist or procedures. There are 5 skills set to be evaluated in RLE 3, withdrawing medication from a vial, and withdrawing medication from ampule, intradermal injection, intramuscular injection and subcutaneous injection. All skill sets follow several steps and the clinical instructor evaluates the student giving 3 points as the highest score for every step performed properly in one procedure. The number of steps for every procedure and the number of procedures for every RLE class varies. All points acquired for every step will be tallied and will become their raw score in the 
procedure; the raw score will be divided to number of items multiplied by 100 to get the procedure score. All 5 procedures will be tallied to get the average, $40 \%$ will be taken from the average to get the equivalent grade. Procedures in the laboratory class were usually performed one at a time, but during the final exam all procedures must be performed at once rotating with assigned evaluators. Equivalent grades were computed manually.

Table 2: Example Computation per Procedure

\begin{tabular}{|l|l|}
\hline Procedure 1 & Score \\
\hline Step 1 & 3 \\
\hline Step 2 & 2 \\
\hline. & \\
\hline . & \\
\hline Step 12 & 2 \\
\hline & \\
\hline Total (Raw Score) & 24 \\
\hline Number of Items & $12($ steps)*3 $=36$ \\
\hline Grade for the Procedure & $27 / 36 * 100=\mathbf{7 5}$ \\
\hline
\end{tabular}

In table 2 a sample computation for a procedure is presented. Depending on the number of steps students will be given certain score for it then tallied as their raw score. Grade for the procedure will be treated by dividing the raw score to the number of items multiplied by 100 . This will be the grade of the student for the procedure.

Table 3: Example Return Demonstration Grade

\begin{tabular}{|l|l|}
\hline Skills & Grade \\
\hline Intradermal injection & 75 \\
\hline Withdrawing medication from a vial & 94 \\
\hline Intramuscular injection & 60 \\
\hline Withdrawing medication from ampoule & 85 \\
\hline Subcutaneous injection & 70 \\
\hline & \\
\hline Total & 384 \\
\hline Average & $384 / 5=77$ (rounded off) \\
\hline Equivalent grade for Return Demonstration & $40 \%$ of $77=31$ \\
\hline
\end{tabular}

Table 3 shows what the clinical instructor will do or the assigned tabulator during the final exam to compute for the grade of the students in return demonstration which consist a total of $80 \%$ of the final grade of the students in the subject; that is $40 \%$ in laboratory and $40 \%$ in final exam. This is a tedious process because of the number of students to be evaluated most especially during the final exam where the students will do all 5 procedures in the same scheduled date.

\subsection{RLE Scorer}

To address the manual computation of the students' grade, an RLE scorer web forms application was developed. It is based on the Google survey forms and collected data will also be saved in the cloud using Google drive. The app is a simple web based program so it is accessible anywhere through smart phones and tablets for it is designed for android and iOS format. The data will be used for the recording of students' performance in RLE 3 or parenteral drug administration. 

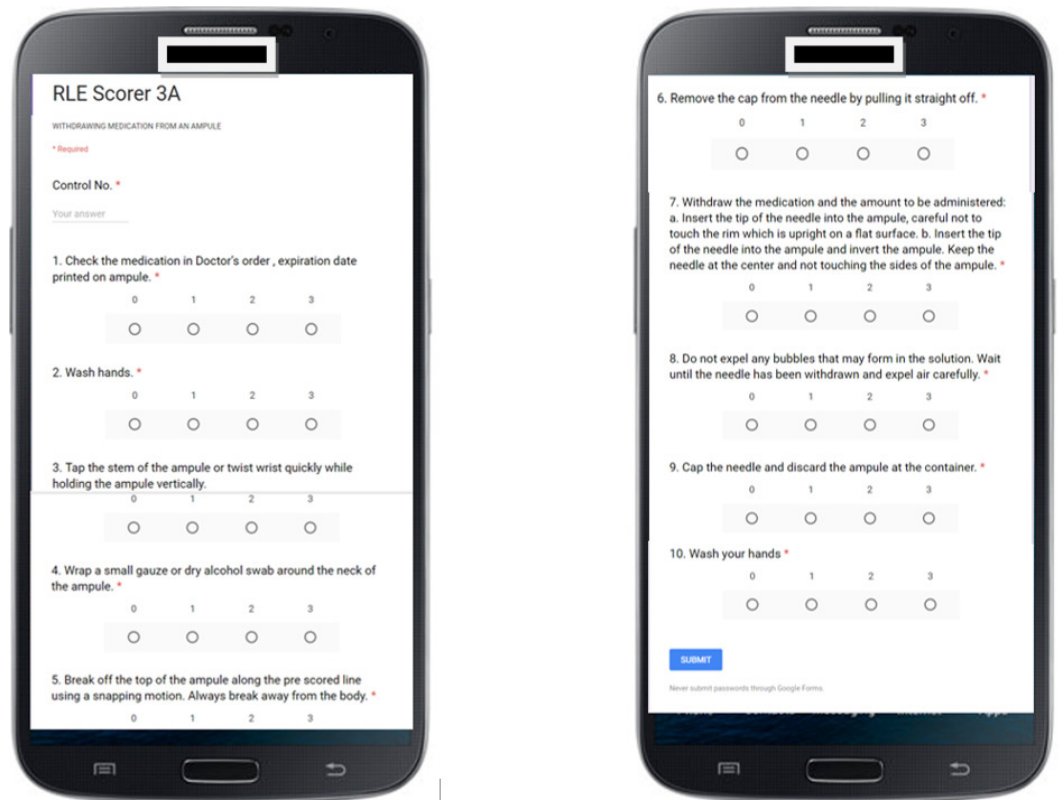

Figure 1: Sample screen of RLE 3AScorer - Withdrawing Medication from ampule

Figure 1 is a sample screen in a smart phone of the RLE 3A Scorer, specifically to tabulate for withdrawing medication from ampule. The user will share the form to a team of clinical instructors that then will access the system throughtheir phones or tablets. The clinical instructor will input the students control number for collection purposes. Then for every step numbered from 1 to 10 for the said skill, user will evaluate the students based on their ability to perform the steps, 3 will be the highest score and 0 as the lowest. The procedure steps was set to required fields to make sure every step was evaluated, then at the end the clinical instructor will click the submit button. All collected data will then be exported in the cloud. At the moment the system is designed for online use, so internet connectivity is a must.

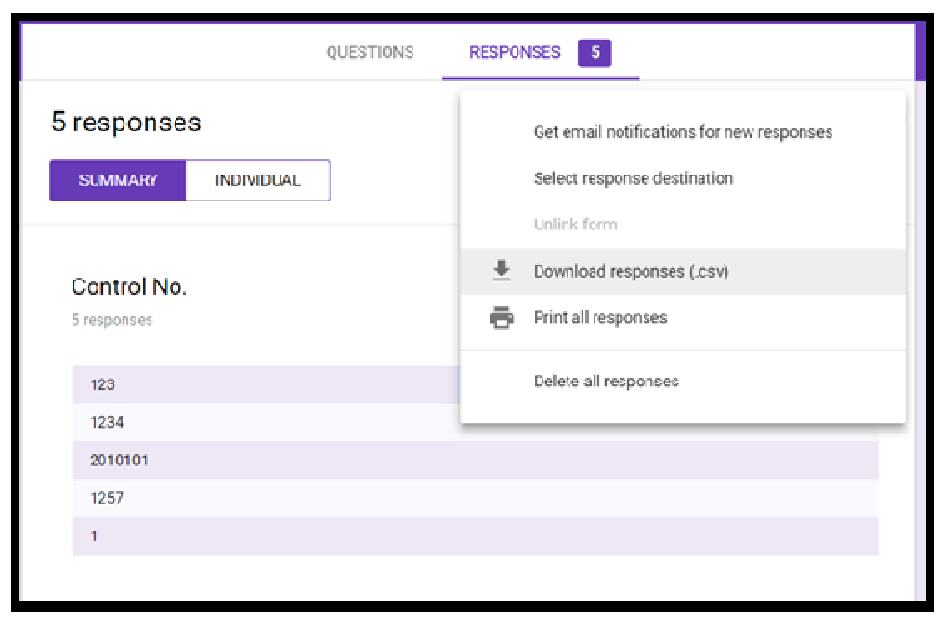

Figure 2: Downloading Collected Survey/performance 
Figure 2 shows the downloading procedure of collected responses of student performance. It is accessed in the cloud through Google drive. The assigned tabulator will download response in the computer and will be saved as CSV format. Since the data is in spreadsheet form the computation will be easily adopted.

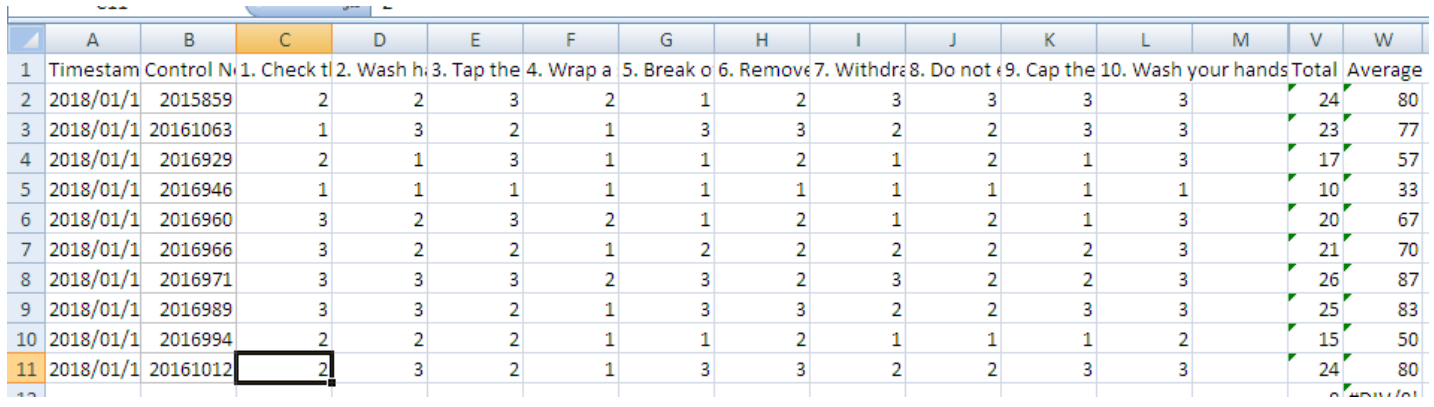

Figure 3: DownloadedResponse(Performance in Withdrawing Medication from ampule)

The downloaded user response is shown in figure 3, Timestamp, Control No. and Steps $1-10$ where the collected response saved in Google drive. The researcher created a template to compute for the Total and Average shown in column V and W. The average will be the grade of the student in the said procedure. Same steps will be used for the rest of the procedures. There are 6 worksheets for this file, the 5 procedures and the tabulation of all procedures to be shown in Figure 4.

\begin{tabular}{|c|c|c|c|c|c|c|c|c|c|c|}
\hline 4 & A & B & C & D & E & $\mathrm{F}$ & G & $\mathrm{H}$ & I & J \\
\hline 1 & No. & Control & $3 \mathrm{~A}$ & $3 B$ & $3 C$ & $3 D$ & $3 E$ & Total & Average & Equivalent \\
\hline 2 & 1 & 2015859 & 80 & 33 & 52 & 61 & 64 & 290 & 58.00 & 23 \\
\hline 3 & 2 & 20161063 & 77 & 81 & 37 & 92 & 72 & 359 & 71.73 & 29 \\
\hline 4 & 3 & B 2016929 & 57 & 56 & 56 & 72 & 64 & 305 & 60.93 & 24 \\
\hline 5 & 4 & 4 2016946 & 33 & 44 & 52 & 64 & 39 & 232 & 46.47 & 19 \\
\hline 6 & 5 & $5 \quad 2016960$ & 67 & 63 & 74 & 81 & 78 & 363 & 72.53 & 29 \\
\hline 7 & 6 & 2016966 & 70 & 37 & 55 & 58 & 88 & 308 & 61.60 & 25 \\
\hline 8 & 7 & $7 \quad 2016971$ & 87 & 50 & 33 & 72 & 50 & 292 & 58.33 & 23 \\
\hline 9 & 8 & 3 2016989 & 83 & 54 & 46 & 72 & 22 & 277 & 55.47 & 22 \\
\hline 10 & 9 & 2016994 & 50 & 54 & 57 & 69 & 78 & 308 & 61.60 & 25 \\
\hline 11 & 10 & 20161012 & 80 & 35 & 33 & 67 & 64 & 279 & 55.80 & 22 \\
\hline
\end{tabular}

Figure 4: Computed Performance in all Procedures

Column $3 \mathrm{~A}$ to $3 \mathrm{~B}$ as shown in figure 4 is linked from the 5 procedure worksheet, so the data was presented per procedure. Total column will compute for the summary of the 5 procedures, Average column for the mean and Equivalent as $40 \%$ of the Average. The Equivalent column will be the students' grade for the Return Demonstration. All excel formula was preformatted as a template for easier organization and computation. The RLE Scorer web form is adaptable to both laboratory return demonstration and final exam. For this research the result of the final exam was used, collected data will then be used for statistical analysis of students' efficacy in parenteral drug administration.

\section{RESUlts AND Discussion}

Collected data by the RLE scorer web forms were structured using table to permit ease of investigation. Frequency distribution, measures of central tendency like weighted mean and standard deviation were presented together with equivalent adjectival rating for the student's 
efficacy in parenteral drug administration. For comparison of data between male and female student independent $t$-test and $\mathrm{p}$ value were used.

\subsection{Frequency Distribution of Respondents}

Table 4: Frequency Distribution of Students Rating in Parenteral Drug Administration

\begin{tabular}{|l|c|c|}
\hline \multicolumn{1}{|c|}{ Rating } & f & \% \\
\hline Very Good $(80-89)$ & 12 & 21.82 \\
\hline Good (70-79) & 14 & 25.45 \\
\hline Passed (60 - 69) & 16 & 29.09 \\
\hline Needs Improvement $(50-59)$ & 8 & 14.55 \\
\hline Poor (Below 50) & 5 & 9.09 \\
\hline Total & 55 & 100 \\
\hline
\end{tabular}

The final return demonstration of $2^{\text {nd }}$ year students of $1^{\text {st }}$ semester school year 2017-2018 frequency of rating is shown in Table 4. A total of 55 students took the exam and 12 of them performed Very Good, 14 performed Good, and 16 reached Passing mark. 8 students Needs Improvement and barely missed the passing mark and 5 performed poorly. Since this data is only $40 \%$ of their final grade, results may differ after adding the other $60 \%$. Since the purpose of this study is efficacy of students, final exam which is more formal as a performance result was used.

\subsection{Weighted Mean of Respondents}

Table 5: Weighted Mean of Students Efficacy in Parenteral Drug Administration

\begin{tabular}{|l|c|c|c|}
\hline Procedure & WM & SD & $\begin{array}{c}\text { Adjectival } \\
\text { Rating }\end{array}$ \\
\hline Intradermal injection & 59.96 & 13.45 & Passed \\
\hline Withdrawing medication from ampoule & 61.40 & 17.82 & Passed \\
\hline Subcutaneous injection & 76.93 & 15.09 & Good \\
\hline Withdrawing medication from a vial & 70.13 & 17.41 & Good \\
\hline Intramuscular injection & 70.98 & 18.87 & Good \\
\hline Overall Performance & 67.88 & 12.43 & Passed \\
\hline
\end{tabular}

As shown in Table 3 the student performed well in Subcutaneous injection procedure with a mean score of 76.93 rated as Good. The same goes with Intramuscular injection and withdrawing medication from a vial with 70.98 and 70.13 respectively with adjectival rating of Good. In withdrawing medication from ampoule the mean score is at 61.40 or Passed and barely making at the passing mark rounded off is Intradermal injection at 59.96. The overall performance is equivalent to 67.88 or right at the passing mark. The rating indicates that the students are good enough to perform the procedure but may need more practice since all procedures are sensitive and might affect patient care. The students will need more exercises to push the result higher. The clinical instructor may focus more on the students' weak points to get a better result and prep the students more before they go to hospital duty the next school year. The continuous experiences of the student nurses' in a variety of practical learning strategies is proven to be an effective 
means of acquiring needed skills set to increasing knowledge, skills, attitude and values to become an excellent nurse practitioner [1].

\subsection{Differences in Responses}

Table 6: Differences in Responses between Male and Female students

\begin{tabular}{|c|c|c|c|c|c|}
\hline Procedure & Gender & WM & SD & t-stat & p value \\
\hline \multirow[t]{2}{*}{ Intradermal injection } & Male & 61.20 & 10.98 & \multirow{2}{*}{0.3729} & \multirow{2}{*}{0.7142} \\
\hline & Female & 59.69 & 14.03 & & \\
\hline \multirow{2}{*}{$\begin{array}{l}\text { Withdrawing medication from } \\
\text { ampoule }\end{array}$} & Male & 69.20 & 20.25 & \multirow{2}{*}{1.3637} & \multirow{2}{*}{0.1916} \\
\hline & Female & 59.67 & 17.00 & & \\
\hline \multirow{2}{*}{ Subcutaneous injection } & Male & 81.90 & 15.63 & \multirow{2}{*}{1.3865} & \multirow{2}{*}{0.1846} \\
\hline & Female & 75.82 & 11.78 & & \\
\hline \multirow{2}{*}{ Withdrawing medication from a vial } & Male & 72.90 & 20.91 & \multirow{2}{*}{0.4761} & \multirow{2}{*}{0.6404} \\
\hline & Female & 69.51 & 16.75 & & \\
\hline \multirow{2}{*}{ Intramuscular injection } & Male & 72.40 & 27.44 & \multirow{2}{*}{0.1904} & \multirow{2}{*}{0.8514} \\
\hline & Female & 70.67 & 16.80 & & \\
\hline \multirow{2}{*}{ Overall Performance } & Male & 71.52 & 14.23 & \multirow{2}{*}{0.9101} & \multirow{2}{*}{0.3763} \\
\hline & Female & 67.07 & 12.02 & & \\
\hline
\end{tabular}

The mean of male $2^{\text {nd }}$ year students in all procedures differs slightly higher in all procedures, where overall performance is at 71.52 for male compared to Female's 67.07 mean score, although a t-stat value of 0.9101 and $p$ value of 0.3763 where it signify no significant difference in mean. Procedure withdrawing medication from ampoule recorded the highest difference in mean were male students' has 69.20 compared to the females 59.67 mean score, though a high standard deviation of 20.25 for male caused the t-stat value at 1.3637 and p-value of 0.1916 or signifying no significant difference in the mean score. Statistically based on $\mathrm{p}$ value the biggest difference is in Subcutaneous injection at 0.1846 although results show no significant difference in the mean. This mean that both male and female students of $2^{\text {nd }}$ year class in Tobruk University performed statistically the same in RLE 3 parenteral drug administration.

Table 7: Differences in Variance Grouped according to Rating

\begin{tabular}{|l|l|c|c|c|c|}
\hline Procedure & \multicolumn{1}{|c|}{ Rating } & WM & Variance & F-value & p $<\mathbf{0 . 0 5}$ \\
\hline \multirow{4}{*}{$\begin{array}{l}\text { Overall } \\
\text { Performance }\end{array}$} & Very Good & 82.68 & 5.01 & & \\
\cline { 2 - 4 } & Good & 74.89 & 5.53 & & \\
\cline { 2 - 4 } & Passed & 64.86 & 10.63 & \multirow{3}{*}{236.0789} & \multirow{2}{*}{0.0000} \\
\cline { 2 - 4 } & Needs Improvement & 55.20 & 9.63 & & \\
\cline { 2 - 4 } & Poor & 42.68 & 16.41 & & \\
\hline
\end{tabular}

Table 7 shows the difference in variance when grouped according to rating. The students with poor performance tends to have the highest variance while the upper group very good have the lowest. With an F-value of 236.0798 and p value below 0.05 level of confidence, the statistics resulted in a significant difference when grouped according to rating.

\section{CONCLUSiON}

RLE Scorer Web Formis a simple web form than can be operated in computers and mobile device. It performed generally well as a data collector and evaluator of student's drug administration performance using handheld devices and internet connection. Having the system 
eases up encoding, collecting of records, organizing and sorting, data retrieval, and report generation. The system is an easy to develop tool for data retrievable in the cloud. The study presented the operational aspects of the College of Nursing in Tobruk University in terms of grading/evaluating nursing students in their return demonstration. The system promotes development of Google forms in data collection and evaluation, an easier method of student grading with automatic computation, Health Informatics and Nursing program in Tobruk University for incorporating new trends in handling data. The statistical results shows that the students performed generally well in parenteral drug administration with a passing mark of 67.88 although no significant difference were seen when students were grouped according to gender. The variance proved to be significantly different based on ANOVA when the students are grouped according to rating. The collected data may be used to improve quality of nursing education by enhancing student's weak points through proper and extensive training and complementing their strong area in the area of parenteral drug administration. The learning of students will be essential when they proceed to actual hospital scenario.

The researchers recommend further study to address factors that may affect the result. More respondents and including other School year level in the study for comparison purposes would advance the result. It is suggested that the faculty members ensure adequate training and proper education in Related Learning Experience. In terms of the web forms, it would be better if all RLE course and procedures will be adapted, data collection in offline mode to avert problems during internet signal loss and/or for the University institution to provide for a stronger internet connection.

\section{REFERENCES}

[1] AloJM,Students Lived Experienced with Team Teaching, Practical Return Demonstration, and Hospital Exposure as Strategies towards Excellent Clinical Nursing Practice (2017), IJSBAR,32 (3), ISSN 2307-4531, 195-206.

[2] Altman G., Buchsel P, Coxon V.,Delmar's Fundamental and Advance Nursing Skills Book (2000). Thomson Learning, ISBN 0-7668-0715-0.

[3] Keill, P., \& Johnson, T. (1993). Shifting gears: Improving delivery of medications. Journal of Nursing Quality Care, 7 (2), 24-33.

[4] PhippsW.,Woods N., Long B., \&CassmeyerV. (1991). Medical-surgical nursing concepts and clinical practice (4th ed., pp. 550-565). St. Louis, MO:Mosby.

[5] K. Goetz. Independent Inquiry on the Perspectives of Team Teaching. 2006.

[6] L.S. Larsen, and C.A. Logan. (2005, Jan.). "Redesign of Clinical Nurse Specialist Role Course for Distance Education: Development, implementation and outcomes." Journal of Nursing Education. Volume 44, Number 1. A Slack Incorporated Publication. Cited in Index Medicos. [14]. S. Ingrid. Team Teaching: Education for the Future. University of Science and Arts of Oklahama, 2006.

[7] N. Abraham. (2005, Jan.). "Teaching with the Nightingale Tracker Technology in Community-Based Nursing Education: A Pilot Study. Journal of Nursing Education, Vol. 44, Number 1. p. 40

[8] S. Quinn and S. Kanter. Team Teaching: An Alternative to Lecture Fatigue. (JC 850 005) Paper in an abstract: Innovation Abstracts (Eric Document Reproductive Service No. ED 251 159), 2000.

[9] B. Robinson and R. Schaible. Collaborative teaching: Reaping the benefits. College Teaching, 43 (2), 57-60, 2005 
[10] "Injection". Cambridge dictionary. Retrieved 2017-07-30

[11] Beyea, S. C., \& Nicoll, L. H. (1996, January). Back to basics: Administering IM injections the right way. American Journal of Nursing, 96 (1), 34-35

[12] Hendrickson, M., Myre, D., Johnson, D., Matlak, M.,Black, R., \& Sullivan, J. (1990). Postoperative analgesia in children: A prospective study of intermittent intramuscular injection versus continuous intravenous infusion of morphine. Journal of Pediatric Surgery, 25 (2), 185-191.

[13] Kumar S.,Impact Of Health Informatics Technology On The Implementation Of A Modified Early Warning Score (Mews) 2015, Health Informatics - An International Journal (HIIJ) Vol.4, No.3/4

[14] “WHO I E-Health,” WHO. [Online]. Available: http://www.who.int/trade/glossary/story021/en/

[15] Hu Y. and Bai G., A Systematic Literature Review Of Cloud Computing In Ehealth (2014), Health Informatics-An International Journal (HIIJ) Vol.3, No.4

[16] "Google Docs, Sheets, Slides", https://en.wikipedia.org/wiki/Google_Docs,_Sheets,_and_Slides. Accessed January 19, 2018.

[17] "Create a survey using Google Forms". Docs editors Help. Google. Retrieved October 30, 2016.

[18] Niroshinie Fernando, Seng W. Loke, \&WennyRahayu, (2013). "Mobile Cloud Computing: A survey”, Future Generation Computer Systems, Vol. 29, pp84-106, Elsevier.

[19] Mendoza J., Buhat-Mendoza D., Tan C., Tobruk University Grading System for College of Nursing Version 2 in Tobruk, Libya (2017), International Journal for Database Management System (IJDMS) Vol. 6, No. 5, December 2017

\section{ACKNOWLEDGEMENT / SOURCE OF SUPPORT}

The authors would like to thank first and foremost God Almighty for the grace and glory of His name, giving us the gift of wisdom and inspiration to write this study. We acknowledge our family and also our friends, for their unwavering support. And to the publisher for the insight in promoting research development, thank you and God bless us all.

\section{Authors}

James neil Neil B. Mendoza obtained his BS Computer Science degree at AMA Computer University in Makati City, Philippines on 2001 and a Master's Degree of Information Technology at Technological University of the Philippines in Manila on year 2005. He has worked as College Instructor for several schools and universities in the Philippines including Informatics Computer Institute, Southern Philippines Institute of Science and Technology and AMA Computer University all in the Computer Studies Department. He held positions as ITE Coordinator and Program Head and later worked as Assistant Professor in a Graduate program. In October of 2009 he went to Libya where he is working as College Lecturer and IT admin staff in Tobruk University (formerly with Omar Al Mukhtar University) in the College of

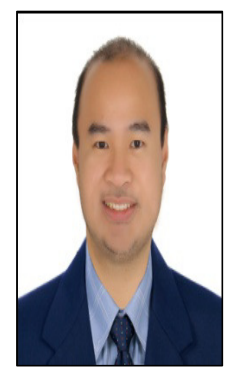
Nursing up to present time. 
Dorothy G. Buhat-Mendoza graduated with a degree in BS Nursing at University of Perpetual Help Manila Campus and obtained her Philippine RN board exam on 2002. She has worked as a nurse at a private hospital in Batangas for three (3) years before becoming a Clinical Instructor at her alma mater. She pursued her Master's Degree in Nursing at University of Lasalette based in Isabela City. In 2011 she went to Libya where she is now working as a Clinical Instructor at Tobruk University (with Omar Al Mukhtar University before) in the College of Nursing. Her field of specialization is in Maternal and Child Nursing.

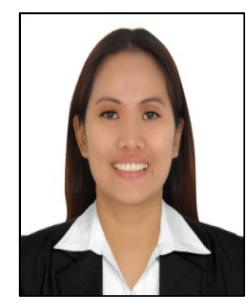

Noraliza Navarrete-Ingua graduated with a degree in BS Nursing at De Ocampo Memorial College, Manila and obtained her Philippine RN board exam on 1993. She has worked as a nurse at a government hospital in Olongapo city and a private hospital in Manila for 3 years before becoming a clinical instructor of College of Nursing at Perpetual Help College Manila. She pursued her Masteral Arts in Nursing at Doctor Carlos Lanting Graduates School based in Quezon City, Manila. In 2011 she went to Libya where she is now working as a Nursing Lecturer at Tobruk University (formerly Omar Al Mukhtar University) in the College of nursing. Her field of specialization is Medical and Surgical Nursing.

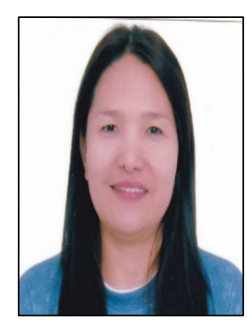

